\title{
Application of Value Analysis Methodology on a Wi-Fi Based Energy Monitor: A Case Study
}

\author{
Utkarsh Tiwari ${ }^{1}$, Omprakash P. ${ }^{2}$, V.S. Giri ${ }^{3}$ \\ 1,2,3 Department of Industrial Engineering and Management, Bangalore Institute of Technology, \\ Bangalore, Karnataka, India \\ E-mail: utkarshrko@gmail.com
}

\begin{abstract}
:
An Energy Monitor is a device used for measuring energy and displaying the energy consumption. It is widely used in industrial and large commercial settings where high power is consumed. It has been observed that energy consumption can be reduced if monitored regularly and right actions are taken based on observations. There exists a need to integrate cloud technology with conventional technology in electronics product space, thus a Wi-Fi based Energy Monitor helps to achieve new heights in energy conservation. This technical paper aims to optimize cost and weight of a Wi-Fi based energy monitor to drive profitability, improve the reliability and increase the Value proposition of the product by the application of Value Analysis Methodology. A cross-functional Value Engineering team was formed to perform a case study on the Wi-Fi based Energy Monitor to identify the potential areas for optimization through Functional Analysis and Decision Matrix. The application of VAVE tools resulted in higher savings, decreased fault rate and reduction in weight of the product which led to a decrease in freight charges for the organization and increased the overall Value to the customers.
\end{abstract}

\section{Keywords:}

value analysis; phases of VE; decision matrix; functional analysis; Wi-Fi based energy monitor; cloud technology; value engineering

\section{Introduction}

Value Engineering originated during the Second World War from the efforts of Lawrence Miles, Jerry Matthew and Harry Erlicher, who were working at General Electric Company. Due to the war, there was a shortage of skilled labor, raw materials and component parts and General Electric wanted substitutes for their products, it was observed that these newfound substitutes resulted in reduced costs, increased functionality of the product or both. A technique for selecting these substitutes was framed and the technique was termed as "Value Analysis".

Value Analysis is a function oriented, systematic team approach to improve the Value of a product, system or process by the critical assessment of the product, system or service to achieve their essential functions at the lowest cost without compromising its performance, reliability, quality and safety.

\section{Review of Literatures}

Value is the lowest cost to reliably provide required function or service at the desired time and place with essential quality. It can be increased by reducing the cost and/or increasing the function or maintaining the function and reducing the cost. The several ways to increase the Value of a product or service is illustrated below: 


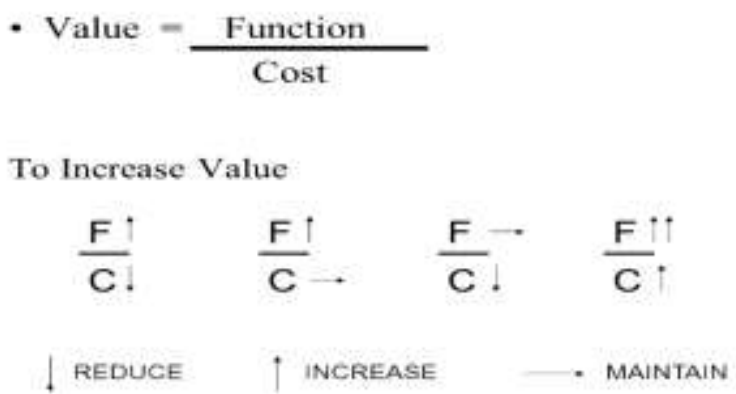

Figure 1. Concept of Value

\section{Research Methods}

\section{Phases in Value Engineering}

The Value Analysis methodology consists of the following phases:

1. Selection Phase

2. Information Phase

3. Functional Phase

4. Creative Phase

5. Evaluation Phase

6. Recommendation Phase

7. Implementation Phase

\section{Selection Phase}

In the selection phase, the Value Engineering team analyses the projects on which Value analysis methodology can be applied and the project which is potentially impacted the most by Value analysis is selected. Some of the factors that affect the selection of the project are:

1) Customer complaints

2) Obsolete design

3) Highly complex assembly

4) High cost components

5) Less profitability

6) Significant failure rate.

7) Difficulty in procuring raw materials

8) High inventory cost

\section{Information Phase}

In the information phase, the Value engineering team gathers all the relevant data such as the estimated costs, design requirements, product specifications, and manufacturing methods and so on. By questioning why, what, when and how, we can secure much more information about the product in question. The collected information is recorded and documented for use in the further phases.

\section{Functional Phase}

The functional approach makes it possible to detect precise area where unnecessary cost originates. The functional approach is one of the most powerful techniques in the VA methodology. The product under study is broken down into parts to determine which part or parts perform the basic function and which part or parts perform the secondary function. The functions are identified and defined in terms of verb and noun and it's categorised between 
basic and secondary. The costs and the worth of the functions are tabulated and the one which has more Value gap is considered in the further phases.

\section{Creative Phase}

After the thorough analysis and understanding of the functional requirements in the Functional Phase, the Value Engineering team must apply creativity techniques such as the Brain Storming technique to look for other ways to fulfil the functional requirement required from the product.

\section{Evaluation Phase}

In the evaluation phase the various alternatives, substitutes and ideas generated in the creative phase are screened and evaluated for their feasibility on the basis of a decision matrix. The alternatives that show the most cost savings and/or functional improvement are considered for the next phase.

\section{Recommendation Phase}

In the recommendation phase the Value engineering team presents the findings of the previous phases to the project stakeholders in order to convince them to implement the alternatives.

\section{Implementation Phase}

The implementation phase is the final phase of the Value Analysis Methodology; in this phase the alternatives put forth by the Recommendation phase are implemented.

\section{Discussion}

\section{Case Study}

The Company faced the problem of not being able to meet the company goals due to underperforming products. Thus, an inter-disciplinary Value Engineering team was formed to identify the underlying issues. The Value Engineering team conducted a Case Study on the Wi-Fi based energy monitor to identify the potential areas for optimisation by applying Value Analysis Methodology. follows:

The Value Analysis Methodology was applied to the Wi-Fi Based Energy Monitor as

\section{Selection Phase}

The Wi-Fi Based Energy Monitor was selected for the following reasons:

1) Cost of the product was relatively high due to redundant components.

2) Assembly of product was complex and increased the lead time.

3) Weight of the product was high which increased the freight charges.

4) Sourcing of components from International suppliers increased the product cost and causes production delays.

5) Failure to meet the annual demand. 


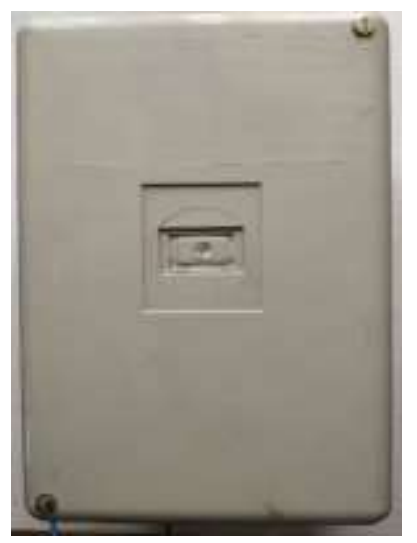

Figure 2. Wi-Fi Based EM1330 Modbus Energy Monitor

\section{Information Phase}

The relevant information regarding the Wi-Fi based Energy Monitor was collected. The summary of the information is as follows:

Product

: Wi-Fi Based Energy Monitor.

Annual Requirement : 4800 as per current data.

Present Cost

: Rs. 5520/-

Design and Development: Additional assembly is required to complete the Wi-Fi module.

Procurement

: International procurement is required due to unavailability of local components.

Logistics : High freight charges due to heavy weight of the product.

Weight $\quad: 3.4 \mathrm{Kg}$

Service History $\quad: 10 \%$ Failure rate post final assembly.

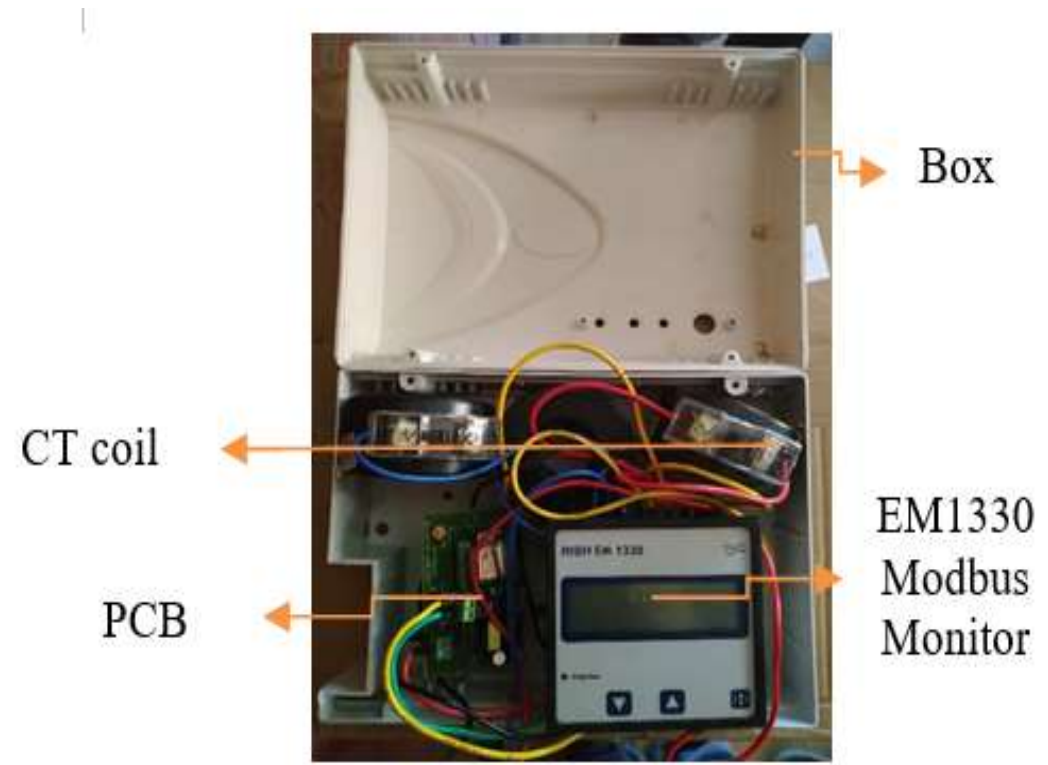

Figure 3. Existing Wi-fi Based Energy Monitor

3. Functional Phase: The objective of the functional phase is to identify functions performed by the components of the Wi-Fi based energy monitor and classifying them in terms of verb and noun, further categorising into basic and secondary function. Function analysis of Wi-Fi based energy monitor is shown in Table 1: 
Table 1. Function analysis- Identification of functions

\begin{tabular}{|c|c|c|c|c|c|c|c|}
\hline \multicolumn{2}{|c|}{ Quantity Part } & \multicolumn{2}{|l|}{ Function } & \multicolumn{2}{|l|}{ Type } & \multicolumn{2}{|c|}{ Assembly } \\
\hline & Name/Description & Verb & Noun & Basic & Secondary & Basic & Secondary \\
\hline \multirow[t]{2}{*}{1} & \multirow{2}{*}{$\begin{array}{l}\text { Advanced } 3 \text { Phase } \\
\text { Energy Monitor } \\
\text { (EM1330 Modbus) }\end{array}$} & Measures & Current & $\mathrm{X}$ & & $\mathrm{X}$ & \\
\hline & & Display & Reading & & $\mathrm{X}$ & & \\
\hline 3 & CT coil & $\begin{array}{l}\text { Step } \\
\text { Down }\end{array}$ & Current & $\mathrm{X}$ & & $\mathrm{X}$ & \\
\hline 1 & $\begin{array}{l}\text { RS485 (UART } \\
\text { converter) }\end{array}$ & Change & Protocol & $\mathrm{X}$ & & $\mathrm{X}$ & \\
\hline 1 & $\begin{array}{l}\text { Wi-Fi } \\
\text { Microcontroller } \\
\text { (ESP12) }\end{array}$ & Enables & Wi-Fi & $\mathrm{X}$ & & $\mathrm{X}$ & \\
\hline 1 & Power Supply & Converts & $\mathrm{AC} / \mathrm{DC}$ & $\mathrm{X}$ & & & $\mathrm{X}$ \\
\hline \multirow[t]{3}{*}{1} & \multirow[t]{3}{*}{ Box } & Contain & Components & $\mathrm{X}$ & & & $\mathrm{X}$ \\
\hline & & Provide & Aesthetic & & $\mathrm{X}$ & & \\
\hline & & Facilitate & Assembly & & $\mathrm{X}$ & & \\
\hline 1 & Connectors & Connect & Components & $\mathrm{X}$ & & & $\mathrm{X}$ \\
\hline
\end{tabular}

Table 2. Function cost worth analysis- Ranking alternatives

\begin{tabular}{|l|l|l|l|l|l|l|}
\hline Function & \multirow{2}{*}{$\begin{array}{l}\text { Present } \\
\text { cost (C) } \\
\text { in Rs. }\end{array}$} & \begin{tabular}{l} 
Worth(W) \\
\cline { 4 - 6 } \\
Verb
\end{tabular} & $\begin{array}{l}\text { Tentative } \\
\text { alternative }\end{array}$ & $\begin{array}{l}\text { Estimated } \\
\text { cost in Rs }\end{array}$ & $\begin{array}{l}\text { Gap } \\
\text { C-W }\end{array}$ & Ranking \\
\hline $\begin{array}{l}\text { Measures } \\
\text { Down }\end{array}$ & Current & 3520 & $\begin{array}{l}\text { Eliminate } \\
\text { Modbus }\end{array}$ & 2950 & 570 & I \\
\hline Change & Protocol & 200 & $\begin{array}{l}\text { Integrate CT } \\
\text { Coil }\end{array}$ & 500 & 200 & II \\
\hline Enables & Wi-Fi & 270 & Eliminate RS485 & 100 & 100 & III \\
\hline Converts & AC/DC & 230 & $\begin{array}{l}\text { Eliminate } \\
\text { Additional } \\
\text { Power Supply }\end{array}$ & 140 & 70 & VI \\
\hline Contain & Components & 300 & $\begin{array}{l}\text { Change } \\
\text { Aesthetic }\end{array}$ & 250 & 90 & IV \\
\hline Connect & Components & 200 & $\begin{array}{l}\text { Eliminate the } \\
\text { need for } \\
\text { additional } \\
\text { assembly }\end{array}$ & 120 & 50 & VII \\
\hline
\end{tabular}




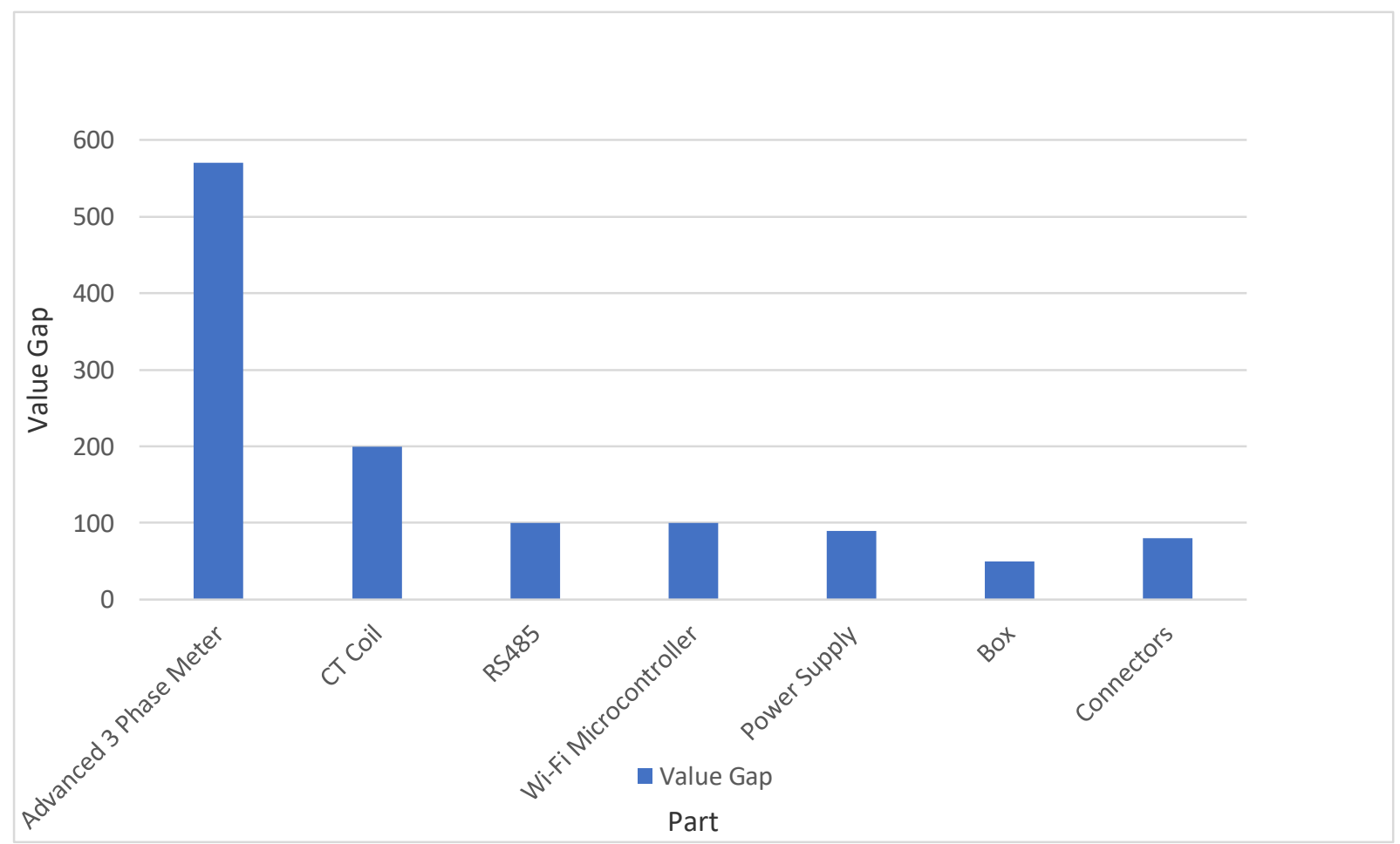

Figure 4. Part vs Value gap

Table 3. Cost Breakup

\begin{tabular}{|l|l|l|l|}
\hline Key Letter & Parts & Function & \% Cost \\
\hline A & Advanced 3 Phase Energy Monitor & Measures Current & 64.94 \\
\hline B & CT Coil & Step down Current & 12.91 \\
\hline C & RS485 & Change Protocol & 5.68 \\
\hline D & Wi-Fi Microcontroller & Enables Wi-Fi & 4.98 \\
\hline E & Power Supply & Converts AC/DC & 4.24 \\
\hline F & Box & Contain Components & 5.53 \\
\hline G & Connectors & Connect Components & 3.69 \\
\hline
\end{tabular}

Parts vs \% Cost

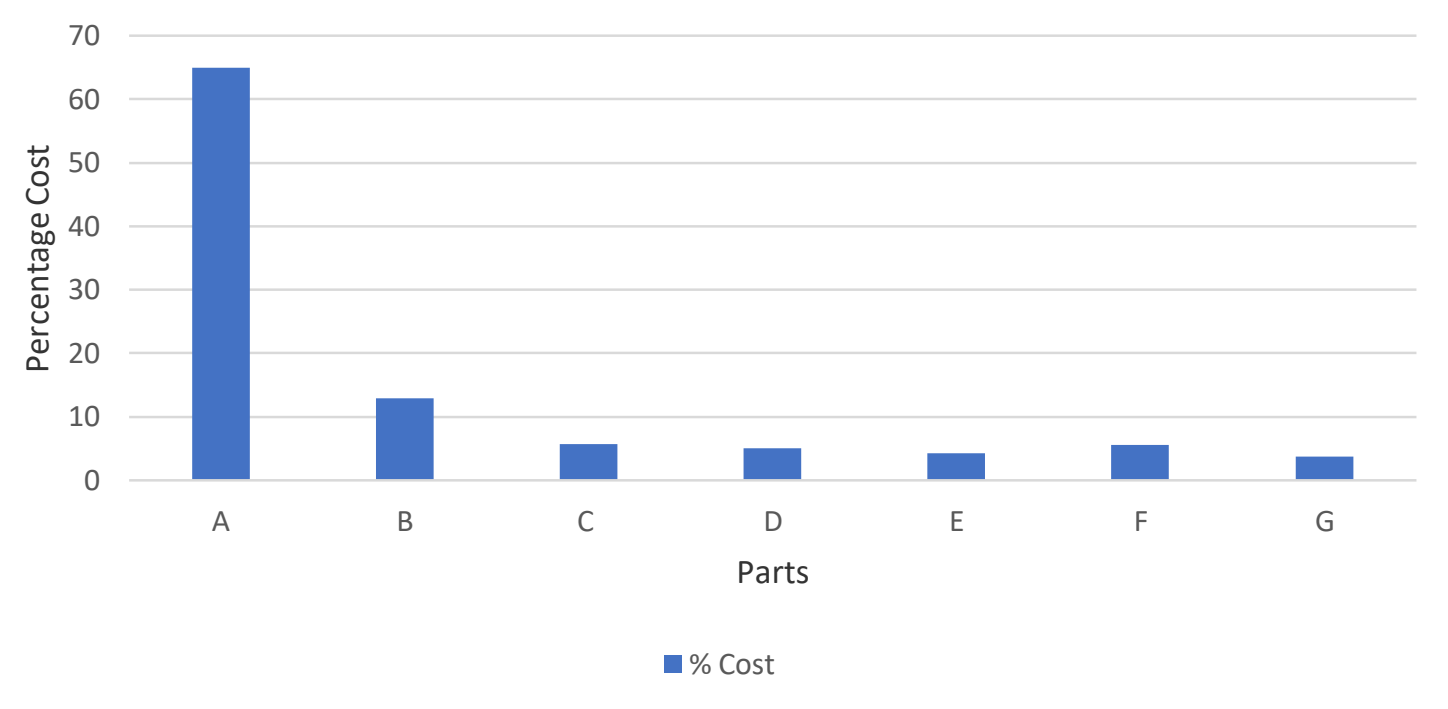

Figure 5. Parts vs Percentage cost 
A

\begin{tabular}{|c|c|c|c|c|c|c|c|}
\hline B & $\mathrm{C}$ & $\mathrm{D}$ & $\mathrm{E}$ & $\mathrm{F}$ & G & Score & Weight \\
\hline A3 & A3 & A3 & $\mathrm{A} 2$ & A1 & $\mathrm{A} 2$ & 14 & 15 \\
\hline \multirow[t]{6}{*}{ B } & B2 & B2 & B2 & B1 & B2 & 9 & 10 \\
\hline & $\mathrm{C}$ & $\mathrm{C} 3$ & $\mathrm{C} 1$ & $\mathrm{C} 1$ & $\mathrm{C} 2$ & 7 & 8 \\
\hline & & $\mathrm{D}$ & D1 & D1 & $\mathrm{D} 2$ & 4 & 5 \\
\hline & & & $\mathrm{E}$ & E1 & E2 & 3 & 4 \\
\hline & & & & $\mathrm{F}$ & F1 & 1 & 2 \\
\hline & & & & & G & 0 & 1 \\
\hline
\end{tabular}

Numerical Evaluation Matrix

\author{
Major Performance-3 \\ Medium Performance- 2 \\ Minor Performance- 1
}

\title{
4. Creative Phase
}

The main theme of creative phase is to find out the best substitution to perform the same function reliably. In this phase, the cross-functional Value Engineering team resorted to Brainstorming techniques to formulate the alternatives to attain the function of Wi-Fi based Energy Monitor which were drawn out in functional phase.

Through brainstorming technique, the following alternatives were generated:

1) Remove Modbus EM1330.

2) Integrate UART with 3 phase energy monitors.

3) Change ESP12 to ESP01

4) Integrate the 3 CT coils.

5) Remove RS485 convertor.

6) Use normal 3 phase energy monitor.

7) Remove additional power supplies.

8) Eliminate the need for additional assembly.

9) Eliminate the need for connectors.

\section{Evaluation Phase}

In this phase the ideas and alternatives generated during the brainstorming session are critically examined and evaluated based on different criteria through a decision matrix. An evaluation matrix is made to check the feasibility of the proposed alternative.

Proposal 1 : The advanced 3 phase Modbus EM1330 Energy Monitor should be replaced with a normal UART integrated 3 phase Energy Monitor which eliminates the RS485 converter and the need of additional power supply. Change ESP12 to ESP01, Integrate the 3 CT coils on a single PCB further integrating it to the 3-phase energy monitor thus eliminating the need for additional assembly and the connectors.

Proposal 2 : The 3 units of CT coil should be integrated by using a single PCB which is further assembled with advanced 3 phase Modbus EM1330 Energy Monitor. Four different criteria were selected by the Value engineering team to evaluate the alternative proposal with the existing design. The criteria are as follows 
Table 4. Evaluation Parameters

\begin{tabular}{|l|l|}
\hline Key Letter & Criteria \\
\hline A & Reliability \\
\hline B & Light Weight \\
\hline C & Maintenance \\
\hline D & Aesthetics \\
\hline
\end{tabular}

A

\begin{tabular}{c|c|c|c|}
\multicolumn{1}{c}{ B } & \multicolumn{1}{c}{ C } & \multicolumn{1}{c}{ D } & Score \\
\hline A3 & A2 & A1 & 6 \\
\cline { 1 - 2 } B & B2 & B1 & 3 \\
& \multirow{2ynn}{*n}{ C } & C1 & 1 \\
& & D & 1
\end{tabular}

Figure 6. Decision Matrix: Matrix for relative weightage

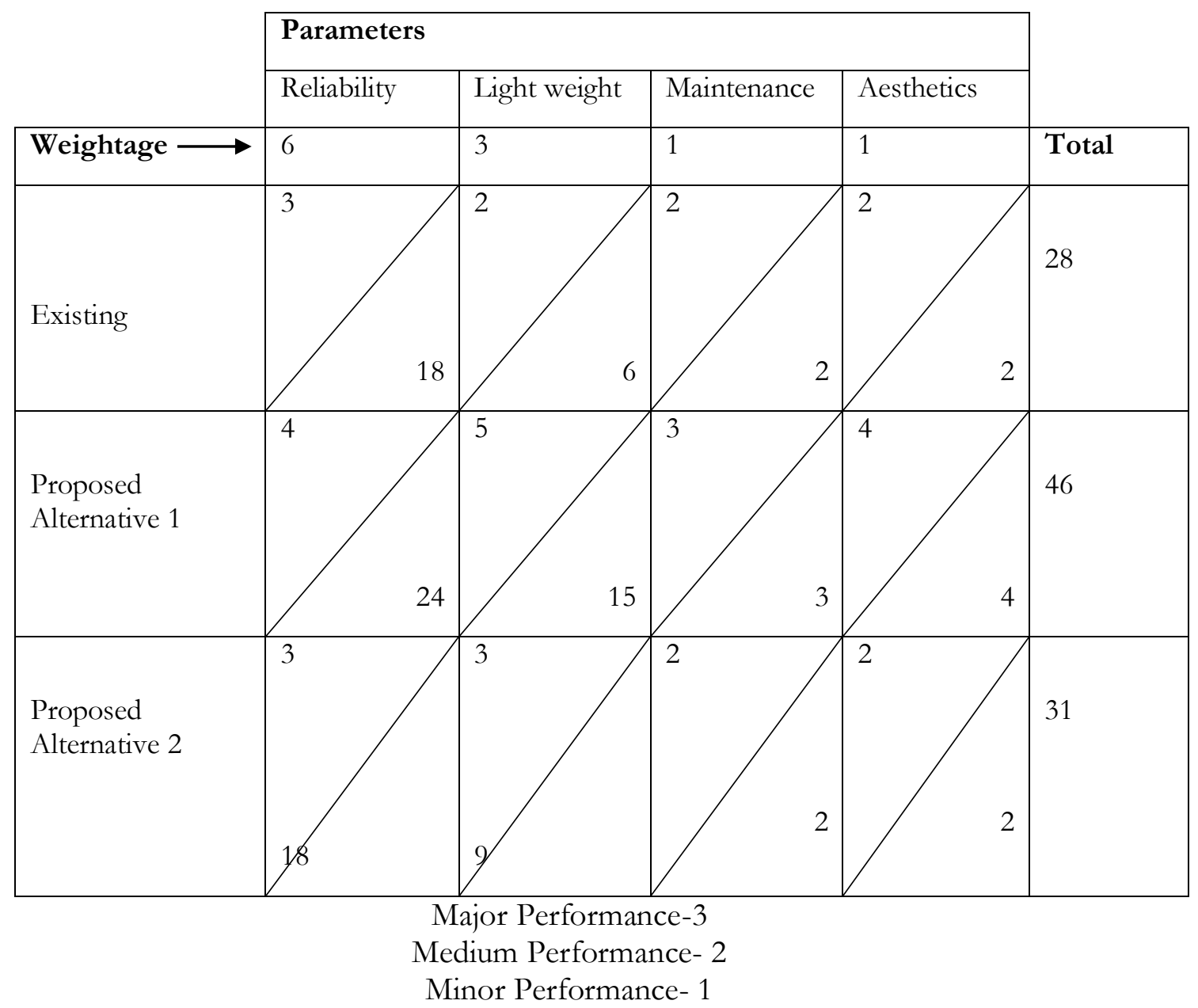

Table 5. Evaluation Matrix

\begin{tabular}{|l|l|}
\hline 5 & Excellent \\
\hline 4 & Very Good \\
\hline 3 & Good \\
\hline 2 & Fair \\
\hline 1 & Poor \\
\hline
\end{tabular}




\section{Recommendation Phase}

The alternative proposal 1 and proposal 2 has been evaluated in the Evaluation Stage. Proposal 1(rating 46) was selected and preferred over proposal 2(rating 31). Proposal 1 was recommended to the management for implementation due to high overall rating in the evaluation phase.

A detailed comparison of existing Wi-Fi based Energy Monitor and the proposed Energy Monitor with the new design was presented to the management. Comparison of existing and proposed alternative is in Table 6 .

Table 6. Comparison of Existing Product and Proposed Product

\begin{tabular}{|l|l|}
\hline Existing & Proposed \\
\hline Complex Assembly & Integrated System \\
\hline Bulky & Compact \\
\hline Heavy (3.4kgs) & Light Weight(1.2kgs) \\
\hline $\begin{array}{l}\text { International } \\
\text { Procurement }\end{array}$ & $\begin{array}{l}\text { Domestic } \\
\text { Procurement }\end{array}$ \\
\hline $\begin{array}{l}\text { High Freight Charges } \\
\text { due to heavy weight }\end{array}$ & Less freight charges \\
\hline & \\
\hline & \\
\hline
\end{tabular}

Cost Breakup for the exsisting and proposed alternative is shown in the following Table 7 and Table 8.

Table 7. Cost break up for the exsisting product with additional assembly cost

\begin{tabular}{|l|l|}
\hline Part & Cost in Rs \\
\hline $\begin{array}{l}\text { Advanced 3 phase Energy } \\
\text { Monitor EM 1330 Modbus }\end{array}$ & 3520 \\
\hline CT Coil & 700 \\
\hline RS485 & 200 \\
\hline $\begin{array}{l}\text { Wi-Fi Microcontroller } \\
\text { ESP12 }\end{array}$ & 270 \\
\hline Power Supply & 230 \\
\hline Box & 300 \\
\hline Connectors & 200 \\
\hline Assembly & 100 \\
\hline Total with Assembly & 5520 \\
\hline
\end{tabular}


Table 8. Cost break up for the proposed product

\begin{tabular}{|l|l|}
\hline Part & Cost in Rs \\
\hline $\begin{array}{l}3 \text { phase UART based } \\
\text { Energy Monitor }\end{array}$ & 3320 \\
\hline $\begin{array}{l}\text { Wi-Fi Microcontroller } \\
\text { ESP01 }\end{array}$ & 180 \\
\hline Integrated 3 CT Coil & 500 \\
\hline Box & 350 \\
\hline Total & 4350 \\
\hline
\end{tabular}

\section{Implementation Phase}

A trial run was performed with 100 samples of the proposed product, the product performed satisfactorily and it was observed that the fault rate of the proposed product was only about $2 \%$ compared to the $10 \%$ fault rate of the existing product. The proposed product was accepted by the management.A cost benefit analysis of existing and proposed Wi-fi based Energy Monitor was done to record overall savings.

Table 9. Cost-Benefit Analysis

\begin{tabular}{|l|l|l|l|}
\hline S. No & Parameters & Existing & Proposed \\
\hline 1 & Cost per piece (Rs.) & 5520 & 4350 \\
\hline 2 & No. of Components & 7 & 4 \\
\hline 3 & Weight per piece (Kg.) & 3.4 & 1.2 \\
\hline 4 & Production capacity (Per Month) & 200 & 400 \\
\hline 5 & Fault Rate & $10 \%$ & $2 \%$ \\
\hline 6 & Reduction in Weight (Kg.) & - & 2.2 \\
\hline 7 & Reduction in Cost & - & 1170 \\
\hline 8 & Monthly Savings & - & $4,68,000$ \\
\hline 9 & Annual Savings & - & $56,16,000$ \\
\hline 10 & Percentage Savings & - & 21.19 \\
\hline
\end{tabular}

\section{Conclusion}

Value Analysis Methodology is a well-defined systematic process that is employed by a versatile team consisting of Value Engineers and Field Specialists to improve the Value of a project, product, process or service. It is a function-oriented team approach where the critical assessment of the product, system or service is performed to achieve their essential functions at the lowest cost without compromising its performance, reliability, quality and safety. In the present competitive market where there is an abundance of Start-Ups competing for market share, budding Start-Ups always face issues due to Lack of Capital, Technological Limitations and Customer Grievances. Hence it is essential that Start-Ups employ Value Analysis Methodology to benefit immensely as shown in this Case Study.

From this Case Study it was observed that upon the application of Value Analysis Methodology to the Wi-Fi Based Energy Meter there was a cost saving of 21\% per unit, a significant weight reduction of $2.2 \mathrm{Kg}$ per unit and a reduction in failure rate from $10 \%$ to $2 \%$. By procuring the new components domestically, the need for international suppliers and freight cost associated with them were eliminated. There was also an increase in the production rate from 2400 units per year to 4800 units per year thus meeting the market demand. 


\section{References}

L.D. Miles "Techniques and Approaches of Value Engineering”, A Reference book.

Anil Kumar Mukopadhyaya "Indian Value Engineering Society (1977-2017) Survey of Forty Years and Selected Essays.

Sharma, A., Belokar, R. M. (2012). Implementation of Value engineering- A case study, International journal of marketing, financial services and management research Vol.1, No.3, ISSN 2277-3622.

Amit Sharma, Harshit Srivastava, R.M. Belokar (2011). A Case Study Analysis Through the Implementation of Value Engineering, International Journal of Engineering Science and Technology (IJEST), Vol. 3, No. 3, ISSN: 0975-5462.

Omprakash P, Utkarsh Tiwari, Varagarahalli Srinivasu Giri. Application of Value-Added Management Practice to Improve Admission Process in Healthcare Centers: A Case Study, American Journal of Engineering and Technology Management. Vol. 3, No. 6, 2018, pp. 69-75. doi: 10.11648/j.ajetm.20180306.11.

Value Analysis of a Rubber Hose Moulding and Assembly Line: A Case Study Pranish M. Naoghare1, Atul R. More2, Sandip S. Patil, International Research Journal of Engineering and Technology (IRJET) - Volume: 04 Issue: 03 | Mar -2017 ISSN: 2395 $-0056$

A Novel Innovative Design Improvement Using Value Engineering Technique: A Case Study Ali Mostafaeipour ; Journal of Optimization in Industrial Engineering 19 (2016) 25-36 dop 27 June, 2015

Value Analysis of steam iron for cost optimization by TATA Technologies - 34th INVEST International Conference, held on December 7 ,2019 in Mumbai.

Achieving Success through Value Engineering: A Case Study Amit Sharma, R.M. Belokar, Member, IAENG: Proceedings of the World Congress on Engineering and Computer Science 2012 Vol II WCECS 2012, October 24-26, 2012, San Francisco, USA

Utkarsh Tiwari, Omprakash P, V.S. Giri, Application of Value Analysis Techniques on a Rucksack: A Case Study, Budapest International Research in Exact Sciences, Vol 2, No 1 (2020), https://doi.org/10.33258/birex.v2i1 